\title{
EDUCAÇÃO NO PROCESSO DE GESTÃO AMBIENTAL PÚBLICA: UMA BASE TEÓRICA PARA INVESTIGAÇÃO DA EDUCAÇÃO AMBIENTAL PRESENTE NOS PLANOS DE COMPENSAÇÃO DE ATIVIDADE PESQUEIRA
}

\author{
Ederson Pinto da Silva ${ }^{1}$; Lucia de Fátima Socoowski de Anello²
}

\section{RESUMO}

Este artigo está situado no campo da Educação no Processo de Gestão Ambiental Pública, mais especificamente na educação ambiental presente nos Planos de Compensação da Atividade Pesqueira, desenvolvidos como condicionantes do licenciamento ambiental das atividades de exploração e produção de petróleo e gás na costa marítima. É parte de um movimento que busca a constituição de uma base teórica que possa dar suporte à investigação sobre como se dão os processos educativos que ocorrem durante 0 desenvolvimento destes planos junto às comunidades de pescadores. Ainda em caráter inconcluso, traz uma base teórica que, ancorada na concepção de educação no processo de gestão ambiental pública e na dialética materialista, pretende dar sua contribuição para futuras pesquisas em educação ambiental com pescadores artesanais.

Palavras-chave: Educação Ambiental; Pescadores Artesanais; Gestão Ambiental.

\section{EDUCATION IN THE PROCESS OF PUBLIC ENVIRONMENTAL MANAGEMENT: A THEORETICAL BASIS FOR RESEARCH OF ENVIRONMENTAL EDUCATION PRESENT IN THE PLANS OF COMPENSATION OF FISHERIES ACTIVITY}

\section{ABSTRACT}

This article is situated in the field of education in the process of public environmental management, more specifically in the environmental education present in the compensation plans of fishing activity, developed as constraints of the environmental licensing of oil and gas exploration and production activities on the maritime coast. It seeks to constitir a theoretical basis that supports research on how the educational processes that occur during the development of these plans are given to the fishing communities. Still in an unfinished character, it brings a theoretical basis that, anchored in the

1 Mestre em Gerenciamento Costeiro. Doutorando no Programa de Pós-Graduação em Educação Ambiental da FURG. Agência Financiadora: CAPES. E-mail: ederson.tga@gmail.com.

2 Doutora em Educação Ambiental. Programa de Pós-Graduação em Educação Ambiental PPGEA/FURG E-mail: luciaanello@hotmail.com. 
conception of education in the process of public environmental management and in the materialistic dialectic, aims to give its contribution to future research in environmental education with artisanal fishermen.

Keywords: Environmental education; artisanal fishermen; Environmental management.

\title{
Introdução
}

Para Quintas (2006) é da interação entre seres humanos e natureza que emerge o que se conhece por meio ambiente. Entretanto, na medida em que o ser humano é simultaneamente um ser natural e um ser social, a forma de interação dos seres humanos com a natureza é influenciada pela forma de organização social, historicamente construída. Esta forma de interação homem-natureza, ao mesmo tempo que é influenciada pelas relações sociais, gera influência nas mesmas.

\begin{abstract}
No processo de transformação do meio ambiente, de sua construção e reconstrução pela ação coletiva dos seres humanos- são criados e recriados modos de relacionamento da sociedade com o meio natural (ser humano-natureza) e no seio da própria sociedade (ser humano ser humano). Ao se relacionar com a natureza e com outros homens e mulheres, o ser humano produz cultura evidenciada por suas manifestações, ou seja, cria bens materiais, valores, modos de fazer, de pensar, de perceber o mundo, de interagir com a própria natureza e com os outros seres humanos, que constituem o patrimônio cultural construído pela humanidade ao longo de sua história (QUINTAS, 2006, p. 21, grifo do autor).
\end{abstract}

Assim, à medida que a sociedade passa a se organizar sob o modelo de produção capitalista, a soma das relações sociais de produção com as relações sociedade-natureza leva ao que se conhece por desigualdades ambientais, ou seja, "a exposição desproporcional dos socialmente mais desprovidos aos riscos das redes técnico-produtivas da riqueza ou sua despossessão ambiental pela concentração dos benefícios do desenvolvimento em poucas mãos" (ACSELRAD, 2010, p. 109). Desta forma, Acselrad (2010) explica que o que está em jogo no centro do embate acerca da questão ambiental é o modo como as diferentes formas de apropriação e uso dos recursos ambientais se organizam e distribuem no território e como a existência de determinadas formas pode afetar as demais. 
É neste contexto que se insere a gestão ambiental pública como "processo de mediação de interesses e conflitos (potenciais ou explícitos) entre atores sociais que agem sobre os meios físico-natural e construído" (QUINTAS, 2006, p.30). Ao discorrer sobre a gestão ambiental pública, Anello (2009) diz que nesta

o governo estabelece as regras para o uso e o acesso aos recursos ambientais (Licenciamento Ambiental, Zoneamento Ecológico Econômico, Planos de Manejo, Plano Diretor ou Código de Posturas e Obras do Município); ou seja, o Estado tem a função de garantir o interesse de todos e o bem comum em uma visão republicana, ou garante as condições para que a disputa pelo acesso ao recurso aconteça dentro de regras pré estabelecidas, ou ainda garante à burguesia a organização racional e eficiente da exploração dos bens ambientais. (ANELLO, 2009, p. 83).

Como ao tomar as decisões no campo ambiental o Estado "está de fato definindo quem ficará, na sociedade e no país, com os custos e quem ficará com os benefícios advindos da ação antrópica sobre o meio físico-natural ou construido" (QUINTAS, 2006, p.31), conforme Layrargues (2006), para a mudança ambiental, sobretudo em sociedades desiguais, é necessário que a educação ambiental tenha relação não apenas com a mudança cultural, mas também com as mudanças sociais.

Neste sentido, inserem-se algumas concepções de educação ambiental que se articulam com as forças sociais progressistas e que são comprometidas com a mudança social. Dialogando com a teoria crítica, são concebidas sobre grande influência da pedagogia de Paulo Freire que encara a educação como "prática da liberdade" e como ação transformadora, onde

\begin{abstract}
A tomada de consciência não se dá nos homens isolados, mas enquanto travam entre si e no mundo relações de transformação, assim também somente aí pode a conscientização instaurar-se[...]. Este esforço da tomada de consciência em superar-se a alcançar o nível da conscientização, que exige sempre a inserção crítica de alguém na realidade que se the começa a desvelar, não pode ser, repitamos, de caráter individual, mas sim social. [...] a conscientização, que não pode dar-se a não ser na práxis concreta, nunca numa práxis que se reduzisse à mera atividade da consciência, jamais é neutra. Como neutra jamais pode ser a educação. Quem fala em neutralidade são precisamente os que temem perder o direito de usar a ineutralidade em seu favor. (FREIRE, 1977, p. 77).
\end{abstract}

Ancorada neste campo teórico está a educação no processo de gestão ambiental discutida em Quintas (2004). Trata-se de uma concepção de 
educação ambiental que, reconhecendo a assimetria nas arenas da gestão ambiental pública, atua no sentido de fortalecer os grupos sociais mais fragilizados para que os mesmos possam se inserir em melhores condições na disputa travada no âmbito destas arenas. Para este autor,

\begin{abstract}
Por ser produzida no espaço tensionado, constituído a partir do processo decisório sobre a destinação dos recursos ambientais na sociedade, a Educação no Processo de Gestão Ambiental exige profissionais especialmente habilitados, que dominem conhecimentos e metodologias específicas para o desenvolvimento de processos de ensino-aprendizagem com jovens e adultos em contextos sociais diferenciados. Exige, também, compromissos com aqueles segmentos da sociedade brasileira, que na disputa pelo controle dos bens naturais do país, historicamente são sempre excluídos dos processos decisórios e ficam com o maior ônus. Cabe esclarecer que, ao se falar em Educação no Processo de Gestão Ambiental, não está se falando de uma nova Educação Ambiental. Está se falando sim, em uma outra concepção de educação que toma o espaço da gestão ambiental como elemento estruturante na organização do processo de ensino-aprendizagem, construído com os sujeitos nele envolvidos, para que haja de fato controle social sobre decisões, que via de regra, afetam o destino de muitos, senão de todos, destas e de futuras gerações. (QUINTAS, 2004, p. 115-116).
\end{abstract}

Desta forma, ao reconhecer a gestão ambiental pública como espaço tensionado e assimétrico, é preciso que as práticas educativas da Educação no Processo de Gestão Ambiental sejam desenvolvidas no sentido de dar e fortalecer a voz daqueles que historicamente ficaram apenas com o ônus do modelo hegemônico adotado pela sociedade capitalista no uso dos bens naturais. Aqui torna-se essencial a reflexão de Paulo Freire.

Quem, melhor que os oprimidos, está preparado para compreender o terrível significado de uma sociedade opressora? Quem sofre os efeitos da opressão mais intensamente que os oprimidos? Quem com mais clareza que eles podem captar a necessidade da libertação? Os oprimidos não obterão a liberdade por acaso, senão procurando-a em sua práxis e reconhecendo nela que é necessário lutar para consegui-la. Essa luta, por causa da finalidade que the dão os oprimidos, representará realmente um ato de amor, oposto à falta de amor que se encontra no coração da violência dos opressores, falta de amor ainda nos casos em que se reveste de falsa generosidade (FREIRE, 2011, p.57).

No campo da Educação no Processo de Gestão Ambiental estão inseridos os Programas de Educação Ambiental - PEAs desenvolvidos no âmbito do licenciamento ambiental das atividades de exploração e produção de petróleo e gás na zona costeira marítima. Tais programas são estruturados a 
partir de projetos e linhas de ação, os quais são normatizados pela NOTA TÉCNICA CGPEG/DILIC/IBAMA № 01/10.

Neste contexto, o presente artigo é parte integrante de uma pesquisa em Educação Ambiental que pretende investigar como se dão os processos educativos que permeiam os Planos de Compensação da Atividade Pesqueira - PCAPs, uma das linhas de ação dos PEAs, implementados como condicionantes do licenciamento das atividades de petróleo e gás na costa marítima. Sendo parte de um todo maior, o mesmo justifica-se na medida em que tem como objetivo o estabelecimento de um arcabouço teórico inicial para a estruturação da pesquisa de forma geral.

Para uma melhor compreensão, este documento foi estruturado em seções, buscando dar cadência a uma sequência de conceitos e entendimentos que se articulam no contexto da pesquisa. Assim, a próxima seção traz o arcabouço conceitual e teórico do qual faz parte o PCAP. Na sequência, de forma complementar, a terceira seção traz a discussão acerca da pesca artesanal e territorialidade. A quarta seção então traz os elementos teóricos iniciais que servirão como suporte para o desenvolvimento da pesquisa em seu todo. Por fim, são tecidas algumas considerações finais, as quais são acompanhadas da bibliografia consultada para a produção deste trabalho.

\section{Os Planos de Compensação da Atividade Pesqueira - PCAPs no contexto licenciamento ambiental da exploração e produção de petróleo e gás}

No âmbito do licenciamento ambiental das atividades de petróleo e gás na zona marítima costeira, os projetos de compensação são entendidos como um

\footnotetext{
conjunto de procedimentos metodológicos balizadores do financiamento de ações compensatórias de caráter coletivo por parte da empresa licenciada quando, diante de um impacto inevitável, for identificada a interferência sobre a atividade econômica e/ou o quotidiano de determinado grupo social (IBAMA, 2010, p. 3).
}

Neste contexto, os Planos de Compensação da Atividade Pesqueira PCAPs passaram a ser exigidos de forma mais sistemática a partir de 2003, sendo que os mesmos têm o objetivo de "compensar as comunidades pesqueiras devido à interferência causada pela atividade de exploração (de 
petróleo) na pesca, especialmente pela exclusão temporária gerada à atividade" (IBAMA, 2007, p. 8-9).

\begin{abstract}
O Plano consiste em fomentar projetos locais voltados ao fortalecimento da atividade de pesca artesanal e ao uso sustentável dos recursos pesqueiros. O PCAP inclui ações que são definidas em conjunto com as comunidades pesqueiras afetadas, levando em consideração suas necessidades e visando capacitá-las, de maneira a possibilitar a participação efetiva destas na gestão dos recursos ambientais e pesqueiros da região. (IBAMA, 2007, p.9).
\end{abstract}

Segundo IBAMA (2007) a exigência do PCAP está embasada na Política Nacional de Educação Ambiental, instituída pela Lei no 9795/99 e regulamentada pelo Decreto № 4.281/02. Já concepção do PCAP foi orientada pelo documento "Orientações Pedagógicas do Ibama para Elaboração e Implementação de Programas de Educação Ambiental no Licenciamento de Atividades de Produção e Escoamento de Petróleo e Gás Natural" (IBAMA, 2005). Tal documento orienta que os programas de educação ambiental desenvolvidos no âmbito do licenciamento das atividades de petróleo e gás devem "reafirmar o papel estratégico da organização e da participação da coletividade, na gestão dos recursos naturais e na busca de um meio ambiente ecologicamente equilibrado, de acordo com a Constituição Federal" (IBAMA, 2005, p. 6). Assim, segundo o IBAMA, as ações educativas desenvolvidas no contexto das medidas mitigadoras e compensatórias relacionadas ao licenciamento das atividades de petróleo e gás devem promover "processos de ensino-aprendizagem que desenvolvam capacidades que habilitem os grupos sociais a atuarem, efetivamente, na formulação implementação e avaliação destes programas e ações" (IBAMA, 2005, p.7).

Desta forma, pode-se perceber que os PCAPs não foram concebidos apenas como uma ação pontual de compensação para a pesca artesanal, mas tendo o licenciamento ambiental das atividades de petróleo e gás como uma totalidade que assume a educação na gestão ambiental como premissa para as atividades a serem desenvolvidas com os públicos impactados. Esta articulação dos PCAPs com a educação ambiental ainda pode ser verificada no documento NOTA TÉCNICA CGPEG/DILIC/IBAMA № 01/10, que sistematiza um conjunto de normatizações, as quais têm o objetivo de estabelecem "diretrizes para a elaboração, execução e divulgação dos programas de 
educação ambiental desenvolvidos regionalmente, nos processos de licenciamento ambiental dos empreendimentos marítimos de exploração e produção de petróleo e gás" (IBAMA, 2010, p. 1). Nesta Nota Técnica, os PCAPs aparecem como uma das linhas de ação que fazem parte dos Programas de Educação Ambiental.

\begin{abstract}
4.5. Linha de Ação E - Projetos compensatórios para populações impactadas por empreendimentos de curto prazo: desenvolver processos educativos com a participação ampla de comunidades tradicionais e/ou com baixa capacidade de representação institucional e de organização sociopolítica, com o objetivo de diagnosticar suas características socioeconômicas e, desta forma, identificar e hierarquizar demandas que permitam a elaboração de projetos coletivos voltados para a melhoria das condições de vida e de trabalho nas comunidades participantes [...] Os Planos de Compensação da Atividade Pesqueira - PCAPs passam a integrar a linha de ação $E$ naquelas bacias de produção em que já exista o programa de educação ambiental. No entanto, as medidas compensatórias passíveis de implementação no âmbito da linha de ação $E$ não se restringem aos impactos sobre a atividade pesqueira, podendo, mediante verificação de impactos do empreendimento licenciado, alcançar outras atividades produtivas desenvolvidas por populações com as características descritas no item 4.5. (IBAMA, 2010, p. 7).
\end{abstract}

Desta forma, tendo os Planos de Compensação da Atividade Pesqueira como parte dos Programas de Educação Ambiental realizados no âmbito do licenciamento ambiental das atividades exploração e produção de petróleo e gás na costa marítima brasileira, sendo assim os pescadores artesanais sujeitos da ação educativa, torna-se importante verificar quais são as concepções de educação ambiental desenvolvidas no âmbito dos projetos que vêm sendo implementados junto às comunidades de pescadores artesanais e qual a relação de tais concepções com os resultados alcançados pelos projetos. Neste contexto, Pereira (2011) afirma que as orientações pedagógicas do IBAMA remetem, no âmbito da gestão ambiental pública, a processos educativos que teriam o desafio de criar espaços onde os conhecimentos fossem compartilhados, promovendo o diálogo entre grupos sociais com interesses afins, tendo ainda a intencionalidade política de transformação. Neste sentido, situa concepção de educação ambiental proposta pelo IBAMA no campo da teoria crítica e da pedagogia de Paulo Freire. Entretanto, sua pesquisa aponta para a existência, no âmbito do licenciamento ambiental de petróleo e gás, de processos educativos baseados 
em propostas pedagógicas ecléticas que, embora utilizem expressões que remetam a uma proposta de educação ambiental comprometida com a transformação social, em seu todo se constituem em propostas "não condizentes com o processo educativo de intencionalidade política, diretivo e engajado apregoado por Freire" (PEREIRA, 2011, p. 151).

Neste contexto, espera-se que os processos de educação ambiental no licenciamento devam contribuir para a qualificação e democratização da gestão ambiental pública. Entretanto, a depender das práticas educativas adotadas, ao contrário do esperado pela política pública, eventualmente tais processos podem apenas servir para a manutenção das relações de poder preestabelecidas.

\section{A pesca artesanal e o debate territorial}

Diegues (1973), para estratificação dos pescadores do litoral norte de São Paulo, utilizou os critérios de i) relações de trabalho existentes na unidade produtiva; ii) destino da produção; iii) tecnologia utilizada; iv) ambiente ecológico a ser explorado, e v) tradição de pesca. Com esta análise, descreveu o pescador artesanal como

[...] aquele que na captura e desembarque de toda a classe de espécies aquáticas, trabalha sozinho e/ou utiliza mão-de-obra familiar ou não assalariada, explorando ambientes ecológicos limitados através de técnicas de reduzido rendimento relativo e que destina sua produção, total ou parcial, para o mercado [...] Ele é um profissional quando faz da pesca seu único meio de vida ou quando e da atividade pesqueira que retira seus rendimentos. (DIEGUES, 1973, p.111).

Com esta compreensão, é possível observar que é por meio do trabalho na natureza que o pescador artesanal se efetiva, como trabalhador, como ser e como o profissional que vive da pesca artesanal. Para ser pescador artesanal ele necessita do ambiente ecológico em condições mínimas que garanta a sua produção e reprodução enquanto trabalhador. Contudo, à medida que as classes dominantes vão se apropriando dos territórios para atender seus interesses, vão gerando impactos no meio ambiente e comprometendo a reprodução social dos pescadores. Os impactos que as atividades a serviço da 
acumulação capitalista podem causar ao ambiente são telegraficamente descritos por Marx e Engels quando os mesmos afirmam que

\begin{abstract}
A "essência" do peixe é o seu "ser", a água - para tomar apenas uma de suas proposições. A "essência" do peixe de rio é a água de um rio. Mas esta última deixa de ser a "essência" do peixe quando deixa de ser um meio de existência adequado ao peixe, tão logo o rio seja usado para servir à indústria, tão logo seja poluído por corantes e outros detritos e seja navegado por navios a vapor, ou tão logo suas águas sejam desviadas para canais onde simples drenagens podem privar o peixe de seu meio de existência (MARX; ENGELS, 2007 p. 46-47).
\end{abstract}

Ora, se a pesca artesanal ocorre em território limitado e se os impactos ambientais decorrentes da exploração da natureza para atender ao interesse do Capital podem comprometer a reprodução social dos pescadores artesanais, torna-se necessário que se compreenda que a relação entre pesca artesanal e atividades de petróleo não se dá somente pelos impactos diretos causados na captura, mas também sobre toda a complexa rede de "nervos vitais" que ligam os pescadores artesanais a determinado território. Anello (2009) destaca que

\footnotetext{
A matriz econômica do petróleo muda a lógica do uso e ocupação do território. Portanto, o contexto em que a ação educativa vai se desenvolver é complexo e deve ser abordado na relação da pesca artesanal com a indústria do petróleo, gerando a necessidade de se conhecer e entender os processos produtivos e suas relações sociais e econômicas para projetar as ações com suas metas e metodologias. (ANELLO, 2009, p.174).
}

Neste contexto, no âmbito do licenciamento ambiental das atividades de petróleo e gás, as ações direcionadas aos pescadores artesanais devem superar as visões fragmentadas que tradicionalmente ajustam suas lentes apenas para o ato de pescar. Cada vez mais é preciso que se tenha uma abordagem territorial para o tratamento da pesca artesanal.

\title{
A dialética materialista como método para análise dos PCAPs
}

Analisar os processos de desenvolvimento e implementação dos Planos de Compensação da Atividade Pesqueira no âmbito dos programas de educação ambiental que integram os processos de licenciamento das atividades de petróleo e gás na zona costeira marítima, mostra-se uma tarefa 
complexa. Para além da discussão do impacto ambiental da atividade de exploração e produção de petróleo no mar estão as dinâmicas populacionais dos pescadores na costa brasileira. Assim, o entendimento da constituição territorial da pesca artesanal na costa brasileira é fundamental para investigar a educação ambiental com os pescadores artesanais.

Para que se investigue as relações entre os territórios pesqueiros artesanais e a influência, nestes territórios, dos processos de desenvolvimento da exploração e produção de petróleo e gás, tendo o PCAP como objeto de pesquisa em educação ambiental na gestão, torna-se fundamental que se busque um método capaz de dar conta de tal complexidade. Um método que torne possível analisar e compreender as múltiplas determinações que se articulam na constituição da realidade.

Neste sentido, mostra-se apropriada a dialética materialista apresentada por Marx (2011) que pode, segundo o Autor, ser um método capaz de ser utilizado para "qualquer todo orgânico" (MARX, 2011, p.76). Entretanto, ao se propor a dialética materialista como método de pesquisa para processos em educação ambiental, é importante destacar, conforme afirma Netto (2011), que nesta perspectiva o método não é um conjunto de técnicas e procedimentos que se vale o pesquisador. O método para Marx,

[...] não é um conjunto de regras formais que se "aplicam" a um objeto que foi recortado para uma investigação determinada nem, menos ainda, um conjunto de regras que o sujeito que pesquisa escolhe, conforme a sua vontade, para "enquadrar" o seu objeto de investigação. [...] O método implica, pois, para Marx, uma determinada posição (perspectiva) do sujeito que pesquisa: aquela em que se põe o pesquisador para, na sua relação com o objeto, extrair dele as suas múltiplas determinações. (NETTO, 2011, p. 5253).

Conforme destacam Tambara e Oliveira (2011) o conhecimento por meio da totalidade não ocorre de modo imediato, sendo necessário que o pesquisador desenvolva um processo de análise e síntese sobre a realidade capturada de forma sincrética. Este processo dialético de chegada ao conhecimento por meio a totalidade concreta também é descrito por Kosik (1976).

Da vital, caótica, imediata representação do todo, o pensamento chega aos conceitos, às abstratas determinações conceituais, mediante cuja formação se opera o retorno ao ponto de partida; desta vez, porém, não mais como ao vivo, mas incompreendido todo da percepção imediata, mas ao conceito do todo ricamente articulado, e 
compreendido. O caminho entre a "caótica representação do todo" e a "rica totalidade da multiplicidade de determinações e das relações" coincide com a compreensão da realidade. $O$ todo, não é imediatamente cognoscível para o homem, embora lhe seja dado imediatamente em forma de sensível, isto é, na representação, na opinião e na experiência. Portanto o todo é imediatamente acessível ao homem, mas é um todo caótico e obscuro. Para que se possa conhecer e compreender este todo, possa torná-lo claro e explicá-lo, o homem tem de fazer um detóur: o concreto se torna compreensível através da mediação do abstrato, o todo através da parte. (KOSIK, 1976, p. 36).'

É necessário, contudo, que na concepção dialética materialista a realidade transforma-se no tempo e, conforme afirmam Tambara e Oliveira (2011), o movimento reflexivo que possibilita o conhecimento da realidade é realizado em consonância com o movimento histórico da sociedade. Assim, a síntese a que chega o pesquisador não está dissociada do movimento histórico-social, tampouco da visão de mundo que possui o sujeito que pesquisa determinada realidade.

\section{Considerações Finais}

Inicialmente é importante considerar que o presente trabalho pertence a um todo que compõe uma pesquisa de doutorado em educação ambiental, mais especificamente no campo da educação ambiental na gestão. Assim, embora seu caráter inconcluso, sua contribuição principal está na articulação das reflexões iniciais que servirão como fios condutores para direcionar o caminho a ser percorrido ao longo da pesquisa.

Não menos importante é a contribuição do presente trabalho para a discussão acerca dos Programas de Educação Ambiental desenvolvidos no âmbito dos processos de licenciamento das atividades de exploração e produção de petróleo e gás na costa marítima. Contribuição mais específica é dada à medida que coloca os Planos de Compensação da Atividade Pesqueira no âmbito dos Programas de Educação Ambiental.

\section{Referências}

ACSELRAD, Henri. Ambientalização das lutas sociais - o caso do movimento por justiça ambiental. Estudos Avançados, [s.l.], v. 24, n. 68, p.103-119, 2010. FAPUNIFESP (SCIELO). http://dx.doi.org/10.1590/s0103-40142010000100010. 
ANELLO, Lucia de Fátima Socoowski de. OS PROGRAMAS DE EDUCAÇÃo AMBIENTAL NO CONTEXTO DAS MEDIDAS COMPENSATÓRIAS E MITIGADORAS NO LICENCIAMENTO AMBIENTAL DE EMPREENDIMENTOS DE EXPLORAÇÃO DE PETRÓLEO E GÁS NO MAR DO BRASIL: A TOTALIDADE E A PRÁXIS COMO PRINCÍPIO E DIRETRIZ DE EXECUÇÃO. 2009. 190 f. Tese (Doutorado) - Curso de Educação Ambiental, FURG, Rio Grande, 2009.

DIEGUES, Antônio Carlos Sant'Ana. PESCA E MARGinalizaÇÃo NO LITORAL PAULISTA. 1973. 190 f. Dissertação (Mestrado) - Curso de Programa de Pós-Graduação em Sociologia, Departamento de Ciências Sociais, USP, São Paulo, 1973.

FREIRE, Paulo. Extensão ou comunicação? Rio de Janeiro: Paz e Terra, 1977. $93 \mathrm{p}$.

FREIRE, Paulo. Pedagogia do Oprimido. 50. ed. Rio de Janeiro: Paz e Terra, 2011. $253 \mathrm{p}$.

INSTITUTO BRASILEIRO DO MEIO AMBIENTE E DOS RECURSOS NATURAIS RENOVÁVEIS. ORIENTAÇÕES PEDAGÓGICAS DO IBAMA PARA ELABORAÇÃO E IMPLEMENTAÇÃO DE PROGRAMAS DE EDUCAÇÃO AMBIENTAL NO LICENCIAMENTO DE ATIVIDADES DE PRODUÇÃO E ESCOAMENTO DE PETRÓLEO E GÁS NATURAL. Brasília: IBAMA, 2005. $18 \mathrm{p}$.

INSTITUTO BRASILEIRO DO MEIO AMBIENTE E DOS RECURSOS NATURAIS RENOVÁVEIS. A Interferência das Atividades Marítimas de Exploração de Petróleo e Gás na Pesca Artesanal: Exigências do Licenciamento Ambiental. [s.i]: IBAMA, 2007. 12 p.

INSTITUTO BRASILEIRO DO MEIO AMBIENTE E DOS RECURSOS NATURAIS RENOVÁVEIS. NOTA TÉCNICA CGPEG/DILIC/IBAMA No 01/10. Rio de Janeiro: IBAMA, 2010. 37 p.

KOSIK, Karel. Dialética do Concreto. 2. ed. Rio de Janeiro: Paz e Terra, 1976. Tradução de Célia Neves e Alderico Toríbio. 6ª Reimpressão.

LAYRARGUES, Philippe Pomier. MUITO ALÉM DA NATUREZA: EDUCAÇÃO AMBIENTAL E REPRODUÇÃO SOCIAL. In: LOUREIRO, Carlos Frederico Bernardo; LAYRARGUES, Philippe Pomier; CASTRO, Ronaldo Souza de (Org.). Pensamento complexo, dialética e educação ambiental. São Paulo: Cortez, 2006. p. 72-103.

MARX, Karl. GRUNDRISSE: Manuscritos econômicos de 1857-1858: esboços da crítica da economia política. São Paulo: Boitempo, 2011. 1285 p. Tradução Mario Duayer e Nélio Scheider.

MARX, Karl; ENGELS, Friedrich. A Ideologia Alemã: Crítica da mais recente filosofia alemã em seus representantes Feuerbach, B. Bauer e Stirner, e do socialismo alemão em seus diferentes profetas (1845-1846). São Paulo: 
Boitempo, 2007. Tradução de: Rubens Enderle, Nélio Schneider e Luciano Cavini Martorano.

NETTO, José Paulo. Introdução ao estudo do método de Marx. São Paulo: Expressão Popular, 2011. 64 p.

PEREIRA, Maria Odete da Rosa. PEAS - PROGRAMAS DE EDUCAÇÃo AMBIENTAL NO LICENCIAMENTO UMA ANÁLISE E UMA PROPOSTA PEDAGÓGICA PARA ALÉM DO CAPITAL SOCIAL. 2011. $171 \mathrm{f}$. Tese (Doutorado) - Curso de Educação Ambiental, FURG, Rio Grande, 2011.

QUINTAS, José da Silva. Educação no processo de gestão ambiental: uma proposta de educação ambiental transformadora e emancipatória. In: MMA. DEA. Identidades da educação ambiental brasileira. Layrargues, P.P. (Coord). Brasília: Ministério do Meio Ambiente, 2004, 156 pg. (113-140).

QUINTAS, José da Silva. Introdução à Gestão Ambiental Pública. Brasília/DF: IBAMA, 2ª Edição, 2006, 100 p.

TAMBARA, Elomar; OLIVEIRA, Avelino Rosa de. Fontes e Métodos na História da Educação. In: XAVIER, Libânia; TAMBARA, Elomar; PINHEIRO, Antonio Carlos Ferreira (Org.). HISTÓRIA DA EDUCAÇÃO NO BRASIL: Matrizes interpretativas, abordagens e fontes predominantes na primeira década do século XXI. Vitória: Edufes, 2011. p. 147-166. 